Nova Southeastern University

NSUWorks

College of Psychology: Faculty Articles

College of Psychology

$11-1-2003$

\title{
Comparison of a Quick Drinking Screen with the Timeline Followback for Individuals with Alcohol Problems
}

Linda C. Sobell

Nova Southeastern University, sobell1@nova.edu

Sangeeta Agrawal

Mark B. Sobell

Nova Southeastern University, sobellm@nova.edu

Gloria I. Leo

Lisa J. Young

See next page for additional authors

Follow this and additional works at: https://nsuworks.nova.edu/cps_facarticles

Part of the Psychology Commons

\section{NSUWorks Citation}

Sobell, L. C., Agrawal, S., Sobell, M. B., Leo, G. I., Young, L. J., Cunningham, J. A., Simco, E. R. (2003). Comparison of a Quick Drinking Screen with the Timeline Followback for Individuals with Alcohol Problems. Journal of Studies on Alcohol, 64(6), 858-861. Available at: https://nsuworks.nova.edu/cps_facarticles/691

This Article is brought to you for free and open access by the College of Psychology at NSUWorks. It has been accepted for inclusion in College of Psychology: Faculty Articles by an authorized administrator of NSUWorks. For more information, please contact nsuworks@nova.edu. 
Authors

Linda C. Sobell, Nova Southeastern University, sobelll@nova.edu

Sangeeta Agrawal

Mark B. Sobell, Nova Southeastern University, sobellm@nova.edu

Gloria I. Leo

Lisa J. Young

John A. Cunningham

Edward R. Simco, Nova Southeastern University, ed@nova.edu 


\title{
Comparison of a Quick Drinking Screen with the Timeline Followback for Individuals with Alcohol Problems*
}

\author{
LINDA CARTER SOBELL, PH.D., A.B.P.P., ${ }^{\dagger}$ SANGEETA AGRAWAL, M.S., ${ }^{\dagger}$ MARK B. SOBELL, PH.D., A.B.P.P., \\ GLORIA I. LEO, M.S. ${ }^{\dagger}$ LISA JOHNSON YOUNG, B.A. ${ }^{\dagger}$ JOHN A. CUNNINGHAM, PH.D., ${ }^{\dagger}$ AND EDWARD R. SIMCO, PH.D. \\ Center for Psychological Studies, Nova Southeastern University, 3301 College Avenue, Fort Lauderdale, Florida, 33314
}

\begin{abstract}
Objective: Two major strategies have typically been used to assess recent drinking: (1) Daily Estimation (DE) measures such as the Timeline Followback (TLFB) and (2) Quantity-Frequency (QF) summary measures. Although QF measures provide a quick and easy measure of consumption, they have been criticized as not being able to capture sporadic and unpatterned drinking (e.g., days that reflect important social and/or health risks). The TLFB, a psychometrically sound drinking assessment method, is able to capture all drinking, including sporadic heavy days and unpatterned drinking. In some situations, however, recall of daily drinking may not be possible or practical (e.g., limited time; no resources). This article compares results obtained by using a QF measure and a DE measure to assess problem drinkers' pretreatment drinking. Method: The current study, part of a large community
\end{abstract}

mail intervention with 825 alcohol abusers, compared results from two drinking measures covering the same time interval that were administered on two different occasions approximately 2.5 weeks apart. Both measures, the Quick Drinking Screen (QDS; a QF summary measure that collected data by telephone) and the TLFB (a self-administered daily estimation measure), collected drinking data for the year prior to the interview. Results: Although the QDS and the TLFB are very different drinking measures, remarkably similar aggregate drinking data were obtained for five drinking variables. Conclusions: When it is not necessary or possible to gather detailed drinking data, the QDS produces reliable brief summary measures of drinking, at least for not severely alcohol dependent individuals. Also, respondents do not appear to use a repetitive response pattern when completing the TLFB. (J. Stud. Alcohol 64: 858-861, 2003)
A $\mathrm{N}$ ARRAY of retrospective self-report drinking measures have been developed and evaluated over the past several decades. These measures have been reviewed on several occasions (Alanko, 1984; Allen and Columbus, 1995; Allen and Wilson, 2003; Room, 1990; Sobell and Sobell, 1995, 2003). For treatment outcome studies, two types of retrospective drinking measures have typically been used: (1) Quantity-Frequency (QF) measures provide retrospective estimates of average or usual consumption; a variety of QF measures exist and none seems to be favored over the others (reviewed in Sobell and Sobell, 2003). (2) Daily Estimation (DE) measures provide estimates of daily drinking; the best known DE measure is the Timeline Followback (TLFB). As described in the above reviews, each measure has advantages and disadvantages that guide the selection of one over another.

Previous studies comparing QF and DE measures have typically found that DE measures provide higher estimates

Received: November 25, 2002. Revision: July 24, 2003.

*The research presented in this article was supported, in part, by National Institute on Alcohol Abuse and Alcoholism grant AA08593. Portions of this article were presented at the annual meeting of the Association for the Advancement of Behavior Therapy, Toronto, Canada, November 1999.

Correspondence should be sent to Linda C. Sobell at the above address, or via email at: sobell1@nova.edu. Sangeeta Agrawal is with the College of Nursing, University of Nebraska Medical Center, Omaha, NB. Gloria I. Leo and John A. Cunningham are with the Addiction Research Foundation Division, Centre for Addiction and Public Health, Toronto, Ontario, Canada. Lisa Johnson Young is with the Anxiety Treatment and Research Centre, St. Joseph's Hospital, Hamilton, Ontario, Canada. of drinking than QF measures (Sobell and Sobell, 1992, 1995, 2003; Sobell, L.C. et al., 1988; Sobell, M.B. et al., 1986), largely because QF measures are not sensitive to sporadic days of heavy drinking. Despite the benefits of DE measures in terms of capturing accurate and detailed drinking data, however, there are times (e.g., limited resources; participant refusal) when it is not possible to obtain TLFB data (Miller and Del Boca, 1994; Sobell and Sobell, 2003; Sobell et al., 2003). Most treatment outcome studies use either a QF or DE measure to assess pre- and posttreatment drinking; however, a recent study (Sobell and Sobell, 2000) used both a DE measure (i.e., TLFB) and a QF measure (Quick Drinking Screen; QDS) to assess problem drinkers' pretreatment drinking and is the focus of this article.

The study described in this article used data from a community-based mail intervention, Promoting Self-Change, to compare results of two different drinking measures (i.e., TLFB and QDS). Because the community intervention study has been described in detail elsewhere (Sobell et al., 1996; Sobell et al., 2002) only details relevant to the present study will be presented here.

\section{Method}

\section{Participant recruitment}

Participants were 825 alcohol abusers who responded to advertisements in Toronto, Canada, and voluntarily participated in the study. Respondents to the advertisements were 
screened by telephone to determine their initial eligibility. The 5-minute telephone screen asked several questions about respondents' drinking and related behaviors and included the Quick Drinking Screen (QDS). Eligible participants received and mailed back the assessment materials, including an informed consent, to a numbered post office box using a stamped self-addressed envelope. The study was approved by a joint Addiction Research Foundation/University of Toronto Institutional Review Board.

As reported elsewhere (Sobell et al., 2002), participant inclusion criteria were (1) reported consumption of, on average, 12 or more drinks ( 1 drink $=13.6 \mathrm{~g}$ absolute alcohol) per week or consumption of five or more drinks on 5 or more days in the past year; (2) was of legal drinking age in Ontario, Canada (19 years old); (3) reported no past history of formal help or treatment for alcohol problems; and (4) signed the informed consent.

\section{Assessment}

After the participants returned their assessment materials, they were randomly assigned to one of two interventions: Information Only or Information Plus Personalized Feedback. Because there were no significant differences in terms of demographic and alcohol-history data for the two groups of participants and no significant differences in outcomes (Sobell et al., 2002), data for the two groups are combined. The mean (SD) age of the 825 participants was 47.5 (11.8) years, and $66.9 \%$ were male. Generally, participants were socially stable as reflected by the fact that $60.6 \%$ were married, $30.7 \%$ had completed university, $60.4 \%$ were employed full-time and $62.3 \%$ worked in white collar jobs. Although participants reported having had a drinking problem for a mean (SD) of 11.4 (9.2) years, the mean (SD) numbers of alcohol-related arrests and hospitalizations were minuscule (0.5 [1.5] and 0.1 [1.3], respectively). On a scale from 0 to 40 , where 8 or greater is suggestive of an alcohol-related problem, participants' mean (SD) Alcohol Use Disorders Identification Test (AUDIT) score (Allen et al., 1997; Conigrave et al., 1995) was 20.2 (6.2). In terms of drinking in the year preceding the intervention, participants reported having drunk on a mean (SD) of 5.4 (1.7) days per week, and they reported consuming a mean (SD) of 5.9 (2.8) drinks on days they drank.

\section{Instruments}

Only the two assessment instruments relevant to this study will be described. The first, the Alcohol Timeline Followback (TLFB), is a retrospective daily estimation measure that seeks to obtain day-by-day estimates of drinking for periods of up to 1 year prior to the administration date (Sobell and Sobell, 1992, 2000, 2003). People are presented with a calendar on which they write important events that serve as memory prompts for estimating daily alcohol consumption over the reporting interval. The TLFB has very good psychometric characteristics, collects information over long intervals, allows for drinking to be described using multiple dimensions, generates a variety of continuous variables that provide different and more precise information about drinking than summary measures and provides a clinically useful picture of a person's drinking (Sobell and Sobell, 2000, 2003; Sobell et al., 2003). The Alcohol TLFB was mailed, with other assessment materials, to respondents who completed it on their own, presumably at their home, and returned it by mail. On average, it takes about 20-30 minutes to complete a 1-year TLFB.

The second instrument, the Quick Drinking Screen (QDS), was administered by telephone by a trained research assistant in 2 to 3 minutes when participants called in response to advertisements (i.e., when they were screened for the study). The QDS contains four questions about drinking: (1) On average in the last 12 months, how many days per week did you drink? (2) When you did drink, on average, how many standard drinks would you have had in a day? (3) How many times in the past 12 months have you had 5 or more standard drinks $[1$ standard drink $=13.6 \mathrm{~g}$ absolute ethanol] on one occasion? (4) In the past 12 months, what was the greatest number of standard drinks you consumed in one day? Responses to Questions 1 and 2 were multiplied to produce a fifth drinking variable: drinks per week over the past year. The mean (SD) number of days between when participants responded to the media solicitations (i.e., answered the QDS questions) and when their assessment materials, including the Alcohol TLFB, were received was 18.2 (21.8).

As described in an earlier report (Sobell et al., 2002), support for the validity of participants' self-reports comes from interviews conducted with collaterals for a randomly selected $10 \%$ of participants. For all postintervention variables (e.g., drinking data, alcohol-related consequences), participants' and collaterals' self-reports were not significantly different using paired $t$ tests $(p>.05)$ and were significantly correlated $(p<.01 ; r$ 's ranged from 0.48 to 0.56 ; e.g., number of days abstinent: $n=56$, participants' mean $[\mathrm{SD}]=9.6[8.7]$, collaterals' mean $[\mathrm{SD}]=8.9$ [9.7], $t=$ 0.70 , NS, $p>.05 ; r=0.56, p<.01)$.

\section{Results}

Data from the five QDS variables were compared with the same five variables generated using data derived from the 1-year pretreatment TLFB that participants completed as part of the mailed assessment materials. Intraclass correlations (ICCs; ICC type $=$ absolute agreement and single measure) and results of paired sample $t$ tests (two-tailed) between the TLFB and the QDS for the five drinking variables are shown in Table 1, along with means and standard 
TABLE 1. Means (SDs), intraclass correlations (ICCs) and results of paired sample $t$ tests between the TLFB and the QDS for five drinking variables for 825 participants

\begin{tabular}{lccccc}
\hline & \multicolumn{2}{c}{ Means (SDs) } & & $\begin{array}{c}t \text { test } \\
\text { Variable }\end{array}$ \\
\cline { 2 - 3 } & TLFB & QDS & & ICCs values \\
\hline $\begin{array}{l}\text { Days drinking per week/ } \\
\quad \text { past year }\end{array}$ & $5.4(1.7)$ & $5.3(1.8)$ & $0.82^{\dagger}$ & -4.1 \\
$\begin{array}{l}\text { Drinks per week/past year } \\
\text { Drinks/drinking day }\end{array}$ & $31.9(18.5)$ & $31.3(18.4)$ & $0.74^{\dagger}$ & -1.2 \\
$\begin{array}{l}\text { Days drinking } \geq 5 \text { drinks per } \\
\quad \text { day/past year }\end{array}$ & $5.9(2.8)$ & $6.2(3.1)$ & $0.68^{\dagger}$ & 2.7 \\
$\begin{array}{l}\text { Greatest number drinks in 1 } \\
\quad \text { day/past year }\end{array}$ & $164.4(117.0)$ & $176.5(136.2)$ & $0.65^{\dagger}$ & 3.3 \\
\hline
\end{tabular}

${ }^{a} 1$ drink $=13.6 \mathrm{~g}$ absolute alcohol; ${ }^{b}$ all two-tailed paired sample $t$ tests were nonsignificant at $\alpha=0.001$ (824 df) except for the variable "days drinking per week/past year" $(p<.001)$.

${ }^{\dagger} p<.001$.

deviations for the five variables. Because of the large sample size and the use of univariate tests for multiple variables, a conservative significance level of .001 was selected. All correlations were significant $(p<.001)$ and all paired $t$ tests were not significant $(\alpha=.001)$ except for the variable “days drinking per week/past year" $(p<.001)$. More striking than the statistical test results is the correspondence between the means and the standard deviations for the two drinking measures.

\section{Evaluation of a response set bias}

One possible explanation for the high agreement between the TLFB and the QDS is that respondents might have used a set pattern for all weeks on the calendar (i.e., used the same pattern for all weeks to save time when completing the calendar). To investigate this possibility, the percentage of the 825 respondents who completed their TLFB using repetitive weekly patterns was evaluated. Because respondents were asked to record their drinking on the calendar for 1 year back from the date of their interview, weekly drinking patterns can be calculated. A repetitive pattern was defined as reporting the same number of drinks consumed on the same days of the week.

Six different index weeks (i.e., earliest 4 weeks and the most recent 2 weeks of the year-long reporting interval) were compared with the respondents' reports for the remaining weeks in the interval. For the 6 index weeks, the percentage of the 825 respondents who had no matching weekly patterns throughout the year-long interval ranged from $60.5 \%$ to $65.7 \%$; conversely, the percentage of the 825 respondents who had identical patterns ranged from $1.9 \%$ to $3.3 \%$. Moreover, only $1.8 \%$ (15/823) of all respondents filled in the TLFB with the same number of drinks for each day on the 1-year calendar. Overall, the large majority of respondents had relatively few matching weeks. For example, using the first index week, $80.6 \%$ of the 825 respondents had 9 or fewer matching weeks in the year. Thus, the agreement between QDS and TLFB measures does not seem to be an artifact of repetitive response patterns.

\section{Discussion}

Summary measures of drinking obtained from 825 alcohol abusers for the year prior to an assessment using two very different drinking measures, the QDS and the TLFB, were remarkably similar for all five drinking variables compared. Even though for one variable, "days drinking per week/past year," the difference between the two methods was statistically significant, in absolute terms the difference was minuscule (TLFB: mean [SD] = 5.4 [1.7]; QDS: mean $[\mathrm{SD}]=5.3[1.8]$ ), amounting to less than $2 \%$ of the mean values and a fraction of the variance. Thus, from the standpoint of clinical significance versus statistical significance, the difference is negligible (Meehl, 1978). Furthermore, in looking at the actual values for the variable "days drinking per week/past year" it is hard to imagine that anyone would draw other than the same conclusions about the participants' drinking from the data obtained by each method. Although one potential explanation for the high level of agreement between the TLFB and the QDS could be that the respondents completed the TLFB in a cursory manner by repeating the same pattern for each week, an evaluation of this possibility found that a very small percentage $(2-3 \%)$ had this pattern, and in some of those cases such a pattern could be accurate. Furthermore, over $75 \%$ of all respondents had relatively few matching weeks during the year.

While past studies (reviewed in Sobell and Sobell, 2003) comparing QF and DE measures have found relatively similar reports for aggregate drinking variables, QF measures typically are not able to capture sporadic and atypical drinking patterns. Consequently, QF measures compared with DE measures usually underestimate consumption. In the present study, the agreement between QF and DE measures was good, including for two variables that reflect heavy drinking (i.e., "days drinking $\geq 5$ drinks" and "greatest number of drinks in 1 day") and that have not been compared in previous studies. The reasons for this discrepancy with other studies are not known and could relate to the phrasing of the QDS questions, the media solicited sample or other factors

The present study suggests that the QDS is an expedient measure for gathering summary drinking data both at assessment and at follow-up. Although the QDS does not provide detailed drinking information (e.g., patterns), it might be a preferred measure in particular situations (e.g., telephone screenings, gathering follow-up data when clients do not want to spend much time in an interview). For example, in the present study, despite the fact that 825 respondents completed a 1-year TLFB calendar at the assess- 
ment and returned it by mail, close to a third of those for whom 1-year follow-up was obtained (189/656) would not complete the follow-up TLFB. The QDS, therefore, was used to collect drinking outcome data from an additional $28.8 \%(189 / 656)$ of the respondents at the 1-year followup. Consequently, follow-up data were gathered from $79.5 \%$ $(656 / 825)$ of respondents rather than the 56.6\% (467/825) retrieval rate that would have occurred if only TLFB data had been used. Participants' concerns with lengthy daily drinking-data collection procedures have confronted other researchers. In Project MATCH, for participants unwilling to spend much time providing follow-up data several simple questions were substituted for the lengthy Form 90 (Miller and Del Boca, 1994). In a survey study, in which less than half of all respondents returned their survey materials, $22 \%$ $(10 / 45)$ of those who randomly received the TLFB returned their materials compared with $51 \%(25 / 49)$ of those who received a graduated frequency summary measure (Cunningham et al., 1999).

Although the presentation order of the QDS and TLFB was not counterbalanced, it is highly unlikely that this influenced the results for two reasons: (1) the nature and format of the way the drinking information was obtained was very different for the two measures (i.e., four questions versus a 360 -day report; by phone with an interviewer versus completed by the respondent him/herself and returned by mail); and (2) on average, there were about 2.5 weeks between when the QDS and TLFB data were collected.

In conclusion, this study suggests that when detailed drinking data are either not necessary or not possible to obtain from problem drinkers the QDS can be used to gather reliable summary measures of drinking. Finally, generalization to more severely alcohol dependent individuals and from those who are not media solicited awaits further research.

\section{References}

Alanko, T. An overview of techniques and problems in the measurement of alcohol consumption. In: Smart, R.G., Cappell, H.D., Glaser, F.B., Israel, Y., Kalant, H., Popham, R.E., Schmidt, W. and Sellers, E.M. (Eds.) Research Advances in Alcohol and Drug Problems, Vol. 8, New York: Plenum Press, 1984, pp. 209-226.

Allen, J.P. And Columbus, M. (Eds.) Assessing Alcohol Problems: A Guide for Clinicians and Researchers. National Institute on Alcohol Abuse and Alcoholism Treatment Handbook Series No. 4, NIH Publication No. 95-3745, Washington: Government Printing Office, 1995.

Allen, J.P., Litten, R.Z., Fertig, J.B. And Babor, T. A review of research on the Alcohol Use Disorders Identification Test (AUDIT). Alcsm Clin. Exp. Res. 21: 613-619, 1997.
Allen, J.P. And Wilson, V. (Eds.) Assessing Alcohol Problems, 2nd Edition, Rockville, MD: National Institute on Alcohol Abuse and Alcoholism, 2003.

Conigrave, K.M., Hall, W.D. and Saunders, J.B. The AUdiT questionnaire: Choosing a cut-off score. Addiction 90: 1349-1356, 1995.

Cunningham, J.A., Ansara, D., Wild, T.C., Toneatto, T. and Koski-Jännes, A. What is the price of perfection? The hidden costs of using detailed assessment instruments to measure alcohol consumption. J. Stud. Alcohol 60: 756-758, 1999.

MeEHL, P.E. Theoretical risks and tabular asterisks: Sir Karl, Sir Ronald, and the slow progress of soft psychology. J. Cons. Clin. Psychol. 46: 806-834, 1978.

Miller, W.R. and Del Boca, F.K. Measurement of drinking behavior using the Form 90 family of instruments. J. Stud. Alcohol, Supplement No. 12, pp. 112-118, 1994.

Room, R. Measuring alcohol consumption in the United States: Methods and rationales. In: Kozlowski, L.T., Annis, H.M., CAppell, H.D., Glaser, F.B., Goodstadt, M.S., Israel, Y., Kalant, H., Sellers, E.M. AND VingiLis, E.R. (Eds.) Research Advances in Alcohol and Drug Problems, Vol. 10, New York: Plenum Press, 1990, pp. 39-80.

Sobell, L.C., Cunningham, J.A., Sobell, M.B., Agrawal, S., Gavin, D.R., Leo, G.I. AND Singh, K.N. Fostering self-change among problem drinkers: A proactive community intervention. Addict. Behav. 21: 817-833, 1996.

Sobell, L.C. And Sobell, M.B. Timeline follow-back: A technique for assessing self-reported alcohol consumption. In: LitTen, R.Z. AND Allen, J.P. (Eds.) Measuring Alcohol Consumption: Psychosocial and Biological Methods, Totowa, NJ: Humana Press, 1992, pp. 41-72.

Sobell, L.C. and Sobell, M.B. Alcohol consumption measures. In: Allen, J.P. And Columbus, M. (Eds.) Assessing Alcohol Problems: A Guide for Clinicians and Researchers. National Institute on Alcohol Abuse and Alcoholism Treatment Handbook Series No. 4, NIH Publication No. 95-3745, Washington: Government Printing Office, 1995, pp. 55-73.

Sobell, L.C. And Sobell, M.B. Alcohol Timeline Followback (TLFB). In: American Psychiatric Association (Ed.) Handbook of Psychiatric Measures, Washington, DC: American Psychiatric Assn, 2000, pp. $477-$ 479.

Sobell, L.C. and Sobell, M.B. Alcohol consumption measures. In: Allen, J.P. AND Wilson, V. (Eds.) Assessing Alcohol Problems, 2nd Edition, Rockville, MD: National Institute on Alcohol Abuse and Alcoholism, 2003, pp. 78-99.

Sobell, L.C., Sobell, M.B., Connors, G. and Agrawal, S. Assessing drinking outcomes in alcohol treatment efficacy studies: Selecting a yardstick of success. Alcsm Clin. Exp. Res., 2003.

Sobell, L.C., Sobell, M.B., Leo, G.I., Agrawal, S., Johnson-Young, L. And Cunningham, J.A. Promoting self-change with alcohol abusers: A community-level mail intervention based on natural recovery studies. Alcsm Clin. Exp. Res. 26: 936-948, 2002.

Sobell, L.C., Sobell, M.B., Leo, G.I. and Cancilla, A. Reliability of a timeline method: Assessing normal drinkers' reports of recent drinking and a comparative evaluation across several populations. Brit. J. Addict. 83: 393-402, 1988.

Sobell, M.B., Sobell, L.C., Klajner, F., Pavan, D. and Basian, E. The reliability of a timeline method for assessing normal drinker college students' recent drinking history: Utility for alcohol research. Addict. Behav. 11: 149-162, 1986. 